\title{
ACOUSTIC DOPPLER VELOCIMETER BACKSCATTER FOR QUANTIFICATION OF SUSPENDED SEDIMENT CONCENTRATION IN SOUTH SAN FRANCISCO BAY
}

\begin{abstract}
Mehmet Öztürk ${ }^{1}$ and Paul A. Work ${ }^{2}$
A data set was acquired on a shallow mudflat in south San Francisco Bay that featured simultaneous, co-located optical and acoustic sensors for subsequent estimation of suspended sediment concentrations (SSC). The optical turbidity sensor output was converted to SSC via an empirical relation derived at a nearby site using bottle sample estimates of SSC. The acoustic data was obtained using an acoustic Doppler velocimeter. Backscatter and noise were combined to develop another empirical relation between the optical estimates of SSC and the relative backscatter from the acoustic velocimeter. The optical and acoustic approaches both reproduced similar general trends in the data and have merit. Some seasonal variation in the dataset was evident, with the two methods differing by greater or lesser amounts depending on which portion of the record was examined. It is hypothesized that this is the result of flocculation, affecting the two signals by different degrees, and that the significance or mechanism of the flocculation has some seasonal variability. In the earlier portion of the record (March), there is a clear difference that appears in the acoustic approach between ebb and flood periods, and this is not evident later in the record (May). The acoustic method has promise but it appears that characteristics of flocs that form and break apart may need to be accounted for to improve the power of the method. This may also be true of the optical method: both methods involve assuming that the sediment characteristics (size, size distribution, and shape) are constant.
\end{abstract}

Keywords: Acoustic Doppler velocimeter, suspended sediment, backscatter, San Francisco Bay

\section{INTRODUCTION}

Suspension, transport, and deposition of sediments in rivers, bays and estuaries are processes of critical importance to understand the overall condition of complex and often highly variable water systems. Sediment is often transported as a suspension. For example, the majority (87-99\%) of sediment delivered to San Francisco Bay during the wet season, from late fall to early spring, arrives as suspended load (Porterfield 1980; Wright and Schoellhamer 2004). Suspended sediments also affect photosynthesis by decreasing light transmission, and the deposition of sediments in shipping channels requires periodic dredging to maintain those channels in navigable conditions.

Nephelometric (optical) turbidity measurements (e.g. Rasmussen et al. 2009) are often a good proxy for suspended sediment concentration (SSC). Optical turbidity sensors are routinely used to provide surrogate estimates of suspended sediment concentration at many locations in San Francisco Bay (Buchanan and Morgan 2012, 2014; Shellenbarger et al. 2013). At most sites in the San Francisco Estuary, turbidity and suspended sediment concentration are closely correlated, and often linearly related. The most significant disadvantage of optical sensors is their extreme sensitivity to biological fouling, particularly in saline estuary waters (Hamilton et al. 1998). Fouling over the instrument's optical window results in erroneous data that must be discarded.

Acoustic backscatter from devices designed to measure water velocities can similarly be used as a proxy for SSC, in some cases (e.g. Hay 1991, Hay and Sheng 1992, Thorne and Hardcastle 1997, Thorne and Hanes 2002), and are impacted less by moderate biological fouling. The basic principle for measurement of suspended sediment concentrations is that acoustic waves passing through a watersediment mixture will scatter and attenuate as a function of sediment, fluid, and instrument characteristics such as acoustic frequency, sediment concentration, and travel distance from the sound source. Each acoustic frequency has a particle size for which it possesses peak sensitivity, and a minimum detectable particle diameter. Theoretically, the best results (maximum sensitivity) are obtained when the circumference of the particle matches the acoustic wavelength, $\lambda$. This requires $D / 2 \times k=1$, where $D$ is the diameter of the particle, and $k$ is the wavenumber (or $2 \pi / \lambda$, Sontek, 1998).

Acoustic velocity measurements are based on the Doppler shift between the signal output frequency and the backscattered frequency. These can generally be classified into two groups: single point measurement devices (typically known as acoustic Doppler velocimeters, or ADVs) and profiling instruments (referred to here as acoustic Doppler profilers or ADPs). ADVs for point measurement of three-dimensional velocities typically involve the use of one transmitter and three acoustic receivers aimed at a small sampling volume near the signal source (typically within 10-15 cm). Profiling instruments typically feature either three or four acoustic beams aimed slightly outward so that they do not intersect.

${ }^{1}$ Civil Engineering Department, Yildiz Technical University , Davutpasa mah. Davutpaşa cad. B-Blok Z-59, Istanbul, 34220, Turkey.

${ }^{2}$ U.S. Geological Survey, California Water Science Center, 6000 J Street Placer Hall, Sacramento, CA, 95819, USA. 
This allows range-gating of the return signal to facilitate computation of three-dimensional velocities at different distances from the sound source(s), averaged over the horizontal footprint of the acoustic beams.

Acoustic backscatter and attenuation are influenced by sediment characteristics (primarily size and shape) and concentration of the suspended material within an ensonified volume. Compensation is typically introduced to account for the influence of the fluid on sound attenuation, as a function of temperature and salinity, and instrument characteristics (frequency and transducer radius). This attenuation is less significant in the case of ADVs, since the measurement volume is typically close to the sound source.

When an acoustic instrument is calibrated for a water system in which suspended sediment properties (size, size distribution, density, shape) display little time dependence, no additional sensor is needed to measure SSC. This approach then provides simultaneous measurements of velocity and concentration via one acoustic sensor that is typically much less susceptible to errors due to biofouling compared with optical sensors. However, the calibration can make the acoustic approach highly site-specific and in some cases strongly seasonally dependent. For example, the biological activity and flocculation can influence the acoustic response of the sensor (Gartner 2004).

Several researchers have investigated the performance of ADVs for prediction of SSC in different natural and simulated water environments, including coastal settings, estuaries and rivers. A few studies are noted below.

Hosseini et al. (2005) studied low-density turbidity currents in a laboratory flume using an ADV. They concluded that an ADV could be suitable and useful for determining the flow structure in turbidity currents. Elçi et al. (2009) estimated SSC in rivers using backscatter from a handheld ADV in quasi-steady flow. MacDonald et al. (2013) studied the effect of flocs on ADV backscatter. They concluded that flocculation modified the backscatter properties of a suspension of sediment particles, compared to a suspension of the same particles in an unflocculated state. Xavier et al. (2015) carried out a set of laboratory experiments to examine the relationship between glass microspheres of various sizes and their acoustic signals recorded by a $6 \mathrm{MHz}$ ADV. They concluded that acoustic return signal amplitudes can be used to estimate concentrations of SSC, if appropriate corrections are applied to the backscattered signals, particularly the attenuation mechanisms.

This study focuses on the evaluation of backscatter obtained from a $6 \mathrm{MHz}$ ADV to estimate SSC that was separately estimated using an optical turbidity proxy. Co-located acoustic and optical sensors were deployed on an intertidal mudflat in the southern portion of San Francisco Bay (SFB), California, USA (Figure 1).

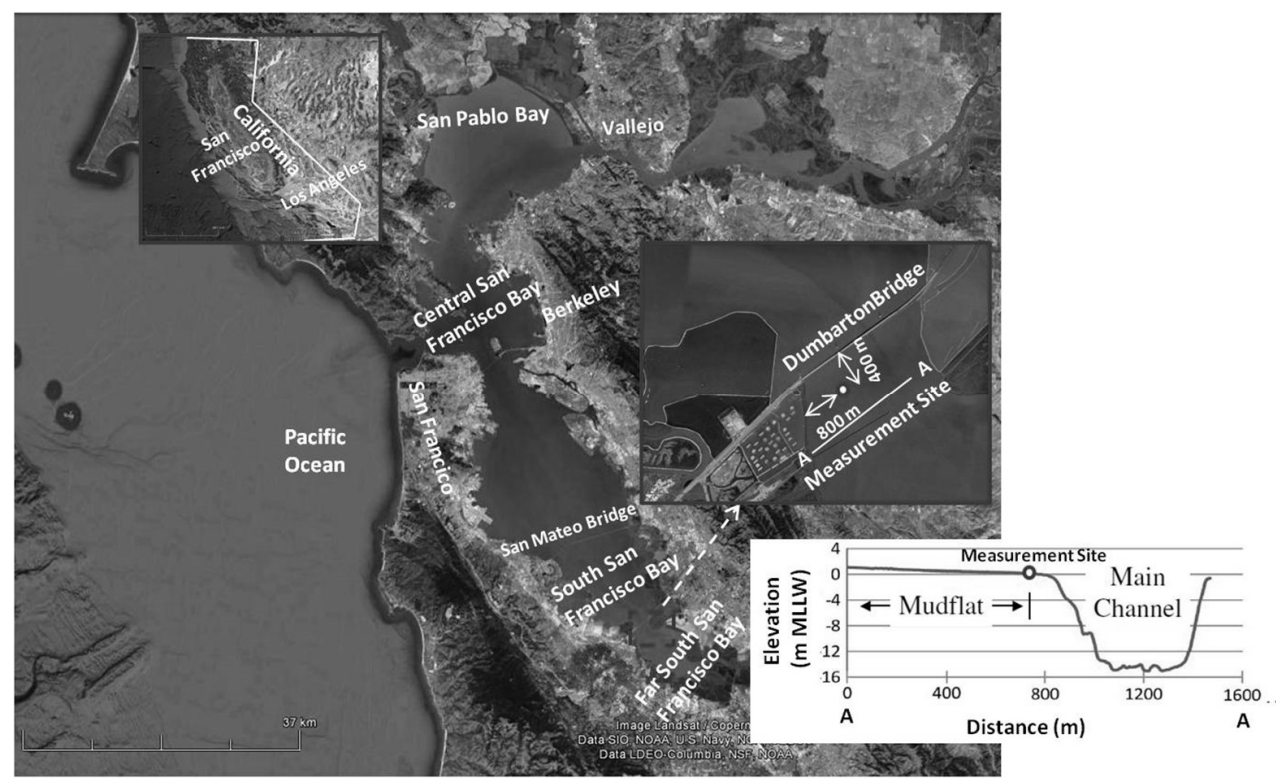

Figure 1. Aerial view of San Francisco Bay and the location of the measurement site near Dumbarton Bridge in South San Francisco Bay. Long-term measurements of turbidity and SSC have been made at a site on a Dumbarton Bridge pier, in the main channel of the estuary. This paper focuses on data collected on the adjacent mudflat, $400 \mathrm{~m}$ south of the bridge and $800 \mathrm{~m}$ from shore. Figure adapted from Jaffe et al. (2011). 


\section{ACOUSTIC BACKSCATTER METHOD FOR ESTIMATION OF SSC}

The most commonly used method for estimating SSC from acoustic backscatter employs a formula based on the sonar equation for sound scattering (reverberation) from small particles. The relationship between estimated SSC and the acoustic backscatter (denoted here as $C B=$ corrected backscatter) can be expressed as (e.g. Gartner 2004):

$$
\log _{10} S S C=A \cdot C B+B
$$

where both $A$ and $B$ are empirical coefficients. The corrected backscatter is the sum of the measured backscatter at the transducer plus the two-way transmission losses. Backscatter is typically measured in units of either decibels or counts. It is typically assumed that counts and decibels are proportional; in this case, amplitude in counts was multiplied by 0.43 to convert to decibels, per manufacturer recommendations. Following Thevenot et al. (1992), $C B$ can be computed as:

$$
C B=M B+2 \cdot T L
$$

where $M B$ is the measured backscatter level (measured backscatter intensity of the received signal) and $2 \cdot T L$ is the estimated two-way transmission loss, assumed to be the same in each direction. The measured backscatter can be taken as the actual reported values, or the reported values minus the noise level. If the noise level is relatively constant, there is negligible difference between the two approaches.

The parameters $A$ and $B$ in Equation (1) can be derived from known $S S C$ and $C B$ data pairs using a least squares fit. SSC is typically measured either via direct methods, such as obtaining water samples in situ and processing to determine sediment content, or via a different indirect method or tool, such as an optical turbidity sensor. The latter approach is taken here.

In its simplified form the sonar equation (Urick 1975) can be written in the form of Equation (3).

$$
M B=S L-2 \cdot T L+T S
$$

where $S L$ is the source level, which is the intensity of the emitted signal that is known or measurable, and $T S$ is the target strength of the suspended sediment, which is dependent on the ratio of acoustic wavelength $(\lambda)$ to particle diameter. The noise level in the measured backscatter averaged 41 counts in this study, with small standard deviation ( 0.5 counts). The two-way transmission loss is defined as

$$
2 T L=2 \alpha_{w} R+2 \alpha_{S} R+20 \log _{10}(R)
$$

where $R$ is the range to the ensonified volume, in meters and each term is in decibels. Equation (4) applies for points that can be considered to be in the far-field, relative to the transducer.

The transmission losses shown in Equation (4) arise due to beam spreading, with this component of the loss increasing as the log of the range, and dissipation of sound energy via interaction with both the water and the media (sediment) suspended in it. The coefficients $\alpha_{w}$ and $\alpha_{s}$ represent the magnitude (per unit travel distance) of these two components of dissipation. $\alpha_{w}$ represents sound absorption by water per unit travel length and is a function of acoustic frequency, salinity, water temperature, and pressure (Schulkin and Marsh 1962). In shallow water (depth $<20 \mathrm{~m}$ ), pressure is not sufficient to exert a significant effect on the absorption coefficient (Alvarez and Jones 2002). $\alpha_{s}$ represents sound absorption by sediment suspended in the water; if concentration varies spatially, Equation (4) would need to be modified to capture this variation. Guidance on choosing both coefficients can be found in Landers et al. (2016). For the sediment concentrations (ranging 20 to $1000 \mathrm{mg} \cdot \mathrm{L}^{-1}$ ), water temperatures and salinities considered in this study, the corrections arising from both modes of attenuation were small enough to be negligible, in part because of the small range $(15 \mathrm{~cm})$ associated with the ADV used here. Details will be shown in the following section.

To summarize, the procedure for estimating SSC from ADV data can be summarized as follows:

1) Estimate coefficients $\alpha_{w}$ and $\alpha_{s}$ based on guidance from the literature. Both are time dependent but in some cases they remain small enough to be negligible, as was the case here.

2) Estimate two-way transmission losses using Equation (4)

3) Compute corrected backscatter, $\mathrm{C} B$, using Equation (2)

4) Apply a best-fit procedure to Equation (1) to determine optimal values of the empirical coefficients $A$ and $B$.

Once the steps above are completed, Equation (1) can then be used in a predictive mode, as long as the conditions do not change sufficiently to warrant recalibration. For example, a significant change in sediment size, size distribution, composition, or degree of flocculation could change the empirical 
relationship between SSC and backscatter. Likewise, the introduction of organic particles could modify the acoustic signal differently than the optical signal.

\section{MEASUREMENT SITE AND INSTRUMENTATION}

Simultaneous, co-located measurements of optical turbidity and acoustic velocity were utilized to investigate the suitability of the method described above for obtaining SSC in the field. The measurements were made on a mudflat close to the Dumbarton Bridge in San Francisco Bay (Figure 1). Since 1993, turbidity and SSC have been measured at a pier on the Dumbarton Bridge. This long-term measurement site lies within the main (deepest) channel of this portion of the estuary (Figure 1). This portion of the bay is referred to as South Bay and it is considered a semi-enclosed embayment, generally vertically well-mixed, except during periods of high local runoff and river discharge. Tides and tidal currents in the bay are dominantly semi-diurnal, with the range of about $3 \mathrm{~m}$ (Conomos et al. 1985; Shellenbarger et al. 2013).

At the bridge, optical turbidity is measured at 15-minute intervals at two depths, and discrete water samples are collected periodically to allow direct measurements of SSC for comparison. The relation between turbidity and SSC is updated annually as new data are obtained. Linear, log, and polynomial relations are all evaluated for goodness of fit. As of 2014, the best-fit, linear relation for the upper sensor ( $25 \mathrm{ft}$ above the bed) was $\mathrm{SSC}=1.6 *$ turb +33.2 , where turb is turbidity in formazin nephelometric units (FNU) and SSC is in milligrams per liter. The corresponding equation for the lower sensor (4 $\mathrm{ft}$ above the bed) was SSC $=2.01 *$ turb +30.8 , with a similar goodness of fit. See station number 373015122071000 at $\mathrm{http}$ //nwis.waterdata.usgs.gov for additional details on the long-term dataset. Figure 2 shows the best-fit, linear relation between SSC and turbidity for the lower sensor, along with the residuals and their probability distribution, compared to a normal distribution.
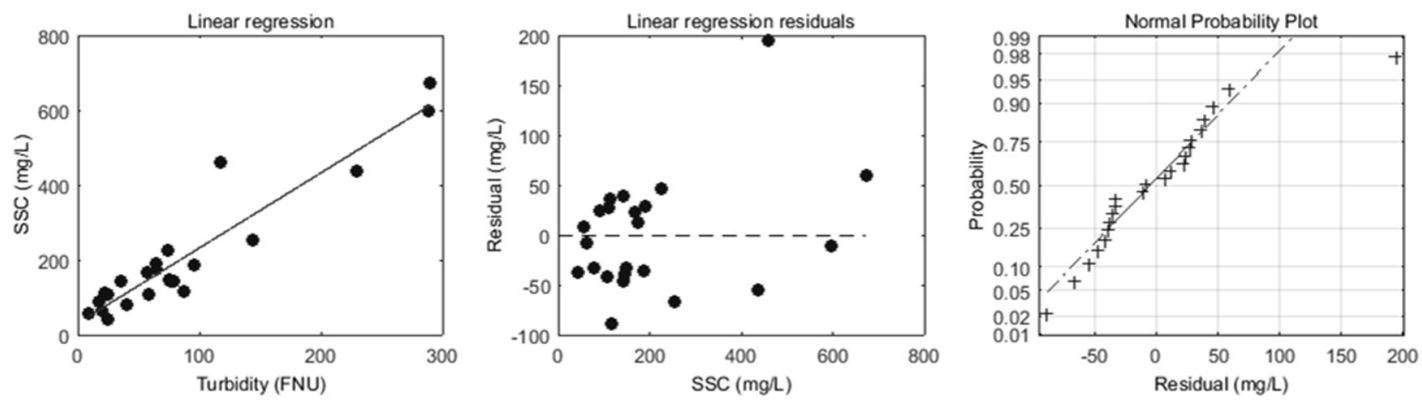

Figure 2. Relationship between optical turbidity and suspended sediment concentration at lower ( $4 \mathrm{ft}$ above bed) sensor at Dumbarton Bridge site. Left panel shows best linear fit to data available as of $2014(n=26)$, middle panel shows the resulting residuals, and the right panel shows the distribution of the residuals, compared to a normal distribution.

In this study, a tripod was deployed on the mudflat beside the main channel of the estuary, just $400 \mathrm{~m}$ south of the Dumbarton Bridge (Figures 1,3). The tripod was deployed at an intertidal spot where the depth above the pressure sensor peaked at $1.9 \mathrm{~m}$ at high tide. Conomos (1963) revealed that the clay size fraction dominates in areas south of the San Mateo and Dumbarton Bridges in San Francisco Bay. Knebel et al. (1977) found that the modal diameter of suspended sediments ranged from 5 to $11 \mu \mathrm{m}$ in South Bay, and Gartner (2004) noted that size of suspended particles can change significantly as flocs form and break apart during a tidal cycle.

Acoustic and optical instrument packages were installed at equal elevations on the tripod, along with a chlorophyll sensor, to record data at 15-minute intervals for approximately 40 days, with two servicing trips within this period. The optical measurements were obtained using a YSI 6025 turbidity sensor (note: the use of trade names and model numbers here does not constitute a product endorsement). Water temperature and specific conductivity were recorded simultaneously, along with turbidity.

Measured turbidity was converted to SSC based on the best fit between bottle sample data and observed optical turbidity at the lower sensor at the bridge, using the following relationship:

$$
S S C=2.01 * \text { turb }+30.8
$$

where turb is the turbidity in FNU. One assumption in using this equation is that the characteristics of the suspended sediment are the same at the mudflat location as the bridge site. The acoustic measurements 
were made using a $6 \mathrm{MHz}$ Nortek ADV which was programmed to collect 1100 samples at $16 \mathrm{~Hz}$ every 15 minutes. Output included 3D velocity, pressure head, and acoustic backscatter.

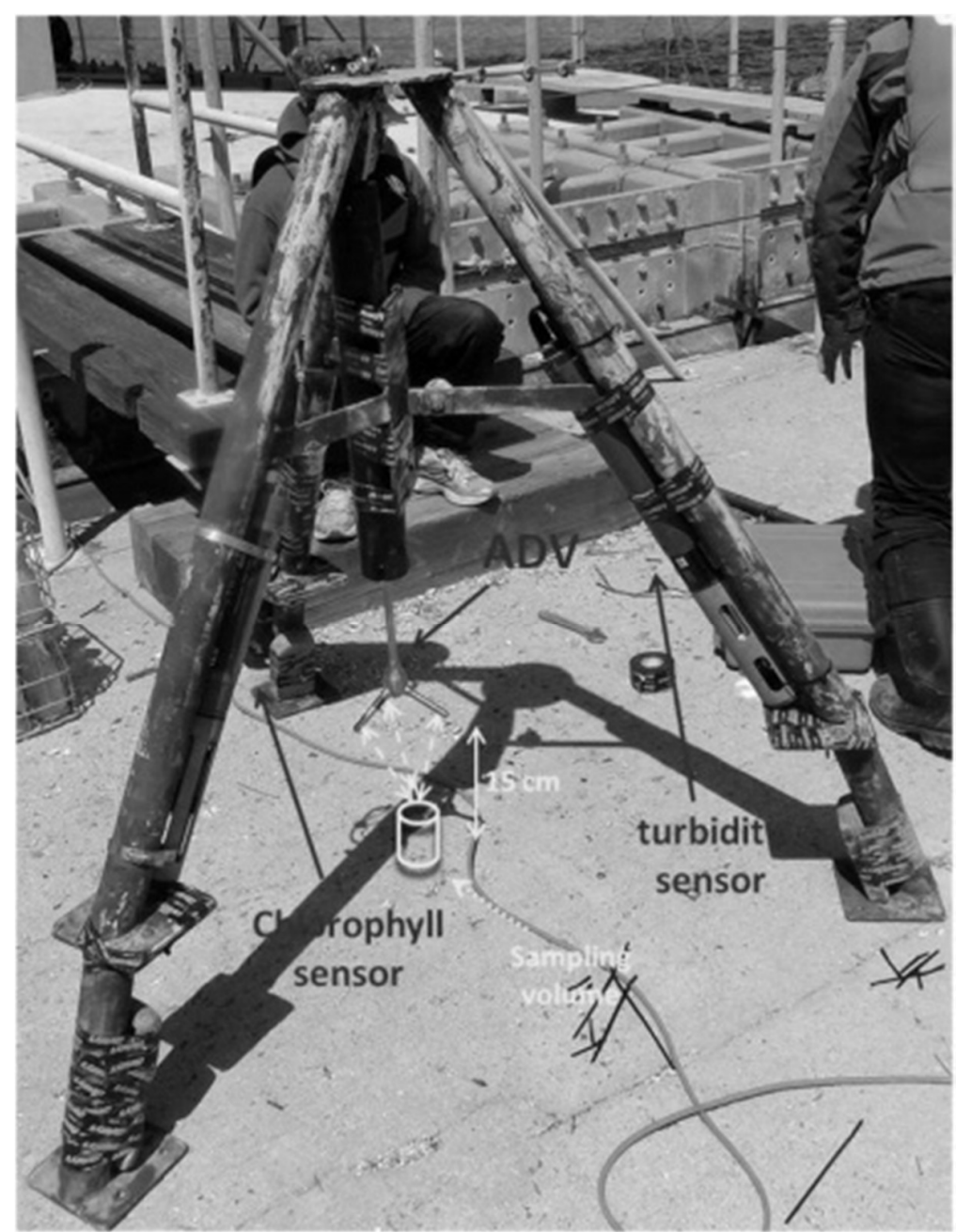

Figure 3. The tripod deployed at the mudflat in South San Francisco Bay. A $6 \mathrm{MHz}$ ADV and an optical turbidity sensor were both installed on the tripod, at the same elevation above the bed. A chlorophyll sensor was also installed. The tripod was installed in the intertidal zone at a site where the depth above the sensors at high tide was $1.9 \mathrm{~m}$.

\section{ACOUSTIC ESTIMATES OF SSC}

The measurement campaign extended 40 days, from late March through late May, 2014. Timedependence in stage, velocity, SSC (computed from optically observed turbidity), temperature, and salinity (computed from observed temperature and specific conductivity) are shown in Figure 4. A histogram of the velocity magnitudes, with flood velocities denoted as negative, is shown in Figure 5, where some ebb asymmetry is evident.

Velocity and SSC are not particularly well correlated; other factors not shown in Figure 4, such as freshwater inflows, delivering sediment to the bay, and wind events, also influence observed turbidity and thus computed SSC. The gradual reduction in salinity that is observed in Figure 4(e) during the measurement period suggests the influence of freshwater inflow. The 40 days shown in Figure 4 represent three separate measurement periods, each spanning roughly three weeks. The balance of the paper will focus on the first and last of these three periods (March 26-April 15 and May 7-28, 2014). These will be referred to as the March and May datasets, and are similar in many ways, but feature one interesting difference that will be noted. 
The May period featured 2216 observations of acoustic parameters, and 2030 records of optical turbidity. Removing records where one or the other was missing, or when the sensors were out of the water, resulted in 1293 pairs of optically and acoustically derived SSC for consideration.

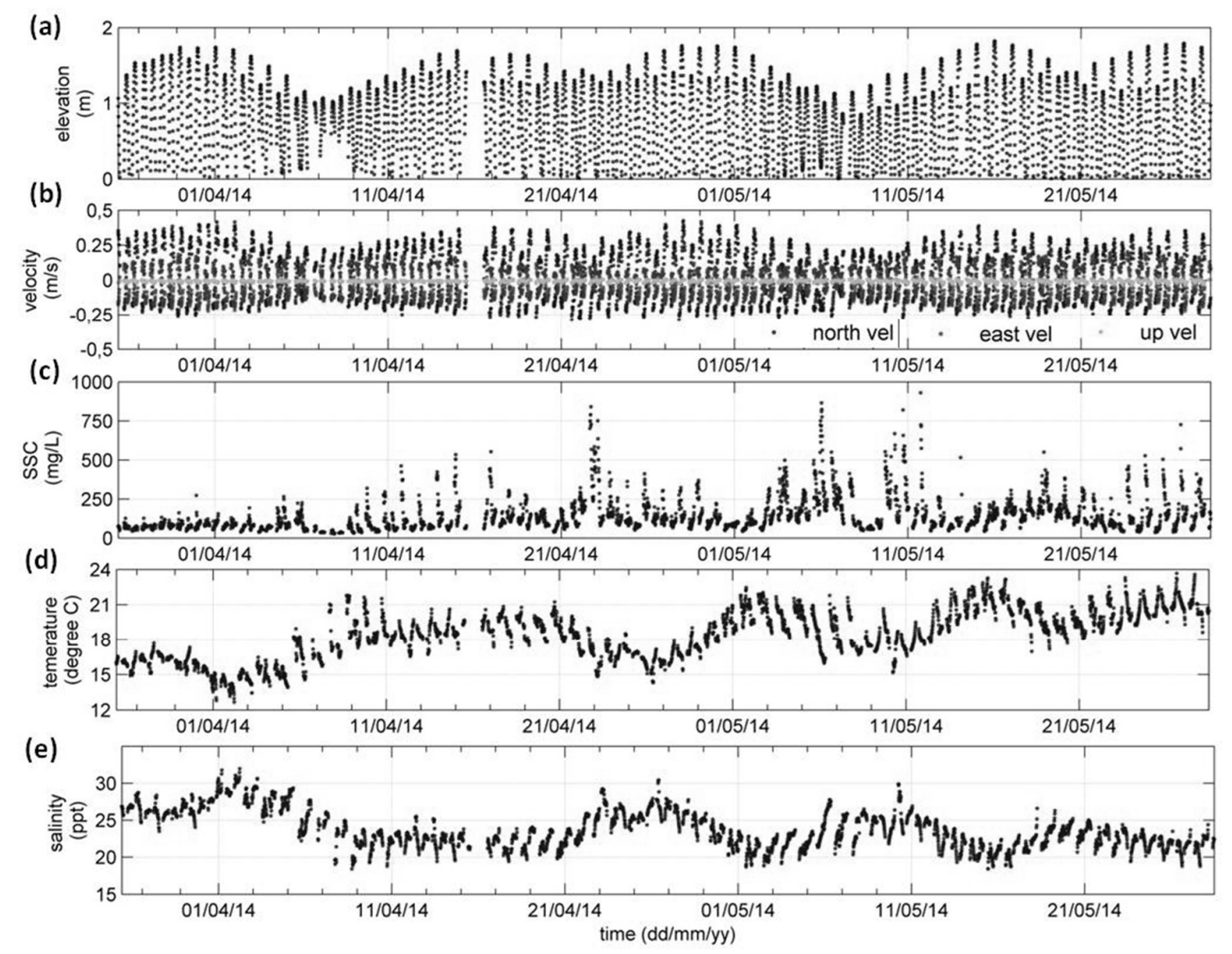

Figure 4. Variation in stage (water depth above sensor), velocity, SSC (computed from turbidity), temperature and salinity at the mudflat measurement site, March 26 - May 28, 2014. SSC computed from observed turbidity, and salinity computed from observed temperature and specific conductivity. Date format is DD/MM/YY, Pacific Standard Time.

The methodology described in the previous section was applied to the Dumbarton mudflat data. The ADV featured a transmission frequency of $6 \mathrm{MHz}$ and a single sampling volume located $15 \mathrm{~cm}$ from the transducer. The corresponding beam spreading correction is $-16.5 \mathrm{~dB}$. The water correction factor was computed as:

$$
\alpha_{w}=\frac{B_{w} f^{2}}{f_{T}}
$$

where $B_{w}=3.38 \mathrm{e}-6, f$ is the instrument frequency in $\mathrm{kHz}$, and $f_{T}=21.9 * 10^{\left(6-\frac{1520}{T+27}\right)}$ and $T$ is water temperature in degrees $C$ (Landers et al. 2016). While $T$ did vary during the measurement campaign, its influence on the water correction factor is negligible, and this factor was evaluated for a constant temperature of 10 degrees $C$. The resulting water correction factor is $1.31 \mathrm{~dB} / \mathrm{m}$, and with a range of 0.15 $\mathrm{m}$, the resulting two-way correction for water attenuation is $0.4 \mathrm{~dB}$.

The sediment correction factor is unknown here, but previous research indicates that it should be $\mathrm{O}(1$ $\mathrm{dB} / \mathrm{m}$ ) and also constant, if sediment characteristics are constant (Landers et al. 2016). This implies that the two-way correction in Equation (4) should be $\sim 0.3 \mathrm{~dB}$. The exact value is not very important, because a) it is an order of magnitude smaller than the measured backscatter, and b) being assumed a constant applied to the corrected backscatter, it will not affect the slope of the curve given by Equation (1), or the goodness of fit. 


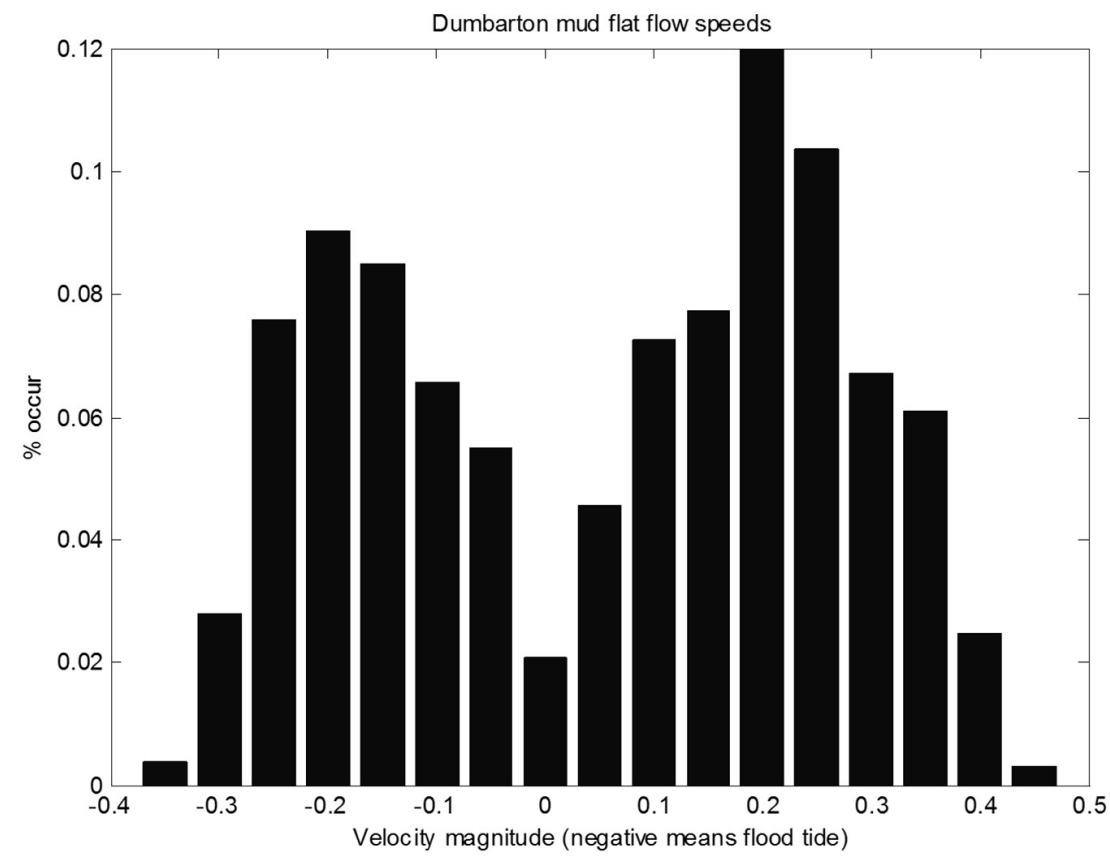

Figure 5. Histogram of flow speeds for May 7-28 deployment. Velocity magnitude is in $\mathrm{m} / \mathrm{s}$.

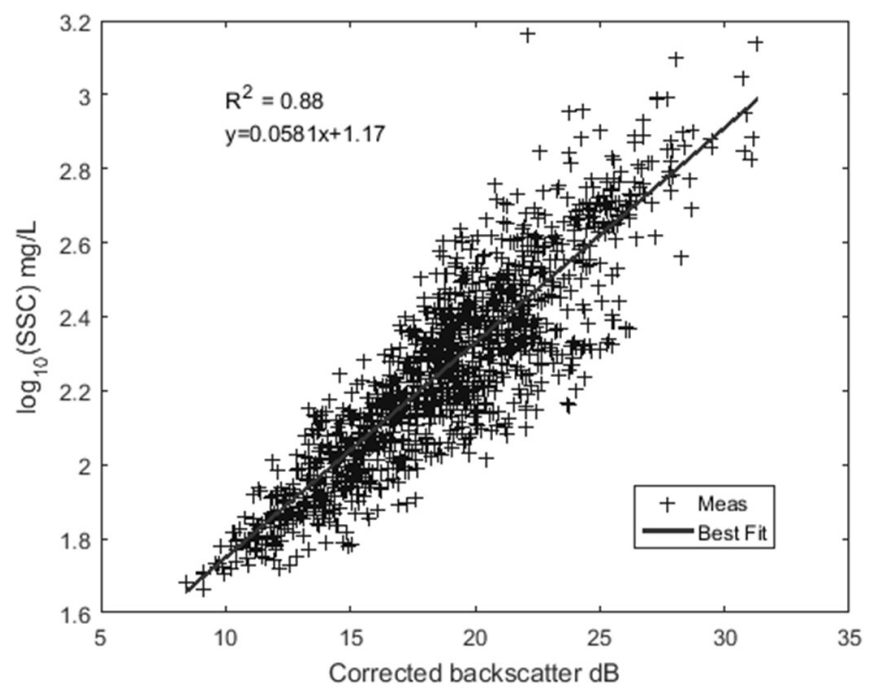

Figure 6. Correlation between optically-derived SSC and corrected backscatter for May 7-28 dataset ( $n=1293)$. Best fit line is $\log _{10}(S S C)=0.0581 \cdot C B+1.17$, where $C B=$ corrected backscatter.

With the corrections thus determined, the corrected backscatter was computed as follows:

$$
C B=(M B-41) * 0.43+(-16.5+0.4+0.3)
$$

or in other words, measured backscatter minus noise plus corrections for beam spreading, water attenuation, and sediment attenuation. Other than the noise, the corrections are all quite small.

To test the methodology described above for estimating SSC from acoustic backscatter, the optically derived SSC data points and the corresponding values of corrected ADV backscatter are plotted against one another in Figure 6. The best-fit equation of the form given by Equation (1) for quantifying SSC was obtained as:

$$
\log _{10}(S S C) \quad 0.0581 \cdot C B+1.17
$$


with a corresponding value of $\mathrm{R}^{2}$ of 0.88 .

\section{INFLUENCE OF TIDAL PHASE AND VELOCITY MAGNITUDE}

Figure 7 shows time dependence in the optically vs. acoustically based estimates of SSC, using Equations (5) and (8), respectively. The goodness of fit is time-dependent, suggesting that time-dependent factors not included in the method by which SSC is being computed are playing a role, or that timedependent factors are influencing the optical measurements more or less than the acoustic data. There is a slight bias, with the mean optically estimated SSC for this measurement period being $10 \mathrm{mg} / \mathrm{L}$ higher than the mean of the acoustic estimates. This arises due to the tendency for the optical approach to report peaks not apparent in the acoustic record.

In the derivation of both Equations (5) and (8), it was implicitly assumed that characteristics of the suspended sediment - size, size distribution, shape, and density - are not changing. In a study conducted very close to the same location as the measurements discussed here, Gartner (2004) observed significant changes in sediment size, as particles flocculated and then the flocs later broke apart. This occurred on a time scale matching the tidal period. Note that for the instrument used here, peak sensitivity should occur for particles with a size of 80 microns, which is similar to the size of the flocs observed by Gartner, but much larger than his reported size of the constituent particles.

Given a suspension of uniformly sized particles that then combine to form flocs, one would observe an increase in water clarity and a corresponding reduction in turbidity, despite the constant suspended sediment concentration. The flocs are larger in size than their constituent particles and will also feature a different average density. So the acoustic signal would also be modified. This means that both Equations (5) and (8), for optical and acoustic, respectively, estimates of SSC, would be modified when the sediment particles flocculate. Given that sound and light attenuation and reflection are not linearly dependent on grain or floc size or density, the two equations would not be expected to change by the same proportions. In other words, an effective increase in particle size via flocculation would modify turbidity and backscatter to differing degrees, changing predicted SSC values from the two signals by different amounts.

The approach utilized to this point did not account for the possibility of floc formation; all data were treated as the same, neglecting the potential for changes in grain or floc size. Assuming that there would be some correlation between floc size (or floc presence) and tidal phase, the latter was investigated for effect on the best-fit relation between optical and acoustic estimates of SSC.

The dataset was divided into periods of ebb and flood flow, based on the sign of the north component of velocity, and the best fits between corrected backscatter and optically derived SSC investigated. Figure 8 shows the result for the May dataset. Given that the flow histograms for ebb and flood flows are similar (Figure 5), the negligible difference in the equations for flood and ebb conditions is unsurprising. Similarly, including only records with velocity magnitudes exceeding $0.2 \mathrm{~m} / \mathrm{s}$ (i.e. roughly half of the records) resulted in a negligible change in predictive power for the May dataset.

The March dataset, however, reveals a distinct difference between flood and ebb conditions (Figure 9). Segregating the data by ebb vs. flood conditions reveals very different predictive equations for the two scenarios. For a given optically observed concentration, ebb flow tends to see a higher acoustic relative backscatter than is observed during flood flow. Segregating the dataset by velocity magnitude or water depth does not reveal a notable difference based on these criteria.

At one point during the measurement campaign, a device for measurement of floc sizes and fall speeds was deployed. Unfortunately data were collected only for less than three hours one afternoon, on April 17, 2014, and the resulting data are not yet available. A difference in particle size between flood and ebb phases of the tide could explain the difference shown in Figure 9.

Clearly for this site, simply knowing the relative backscatter is not sufficient for good estimates of optically derived SSC. The significant difference between flood and ebb conditions that appears in Figure 9 is not evident in the May dataset (Figure 8). Additional data will likely be required to refine the relationship and identify the reason for the seasonal difference. One hypothesis to investigate is whether organic material might be influencing the flocculation process. If fine suspended organic material was present to greater or lesser degrees during the March measurement period, compared to the May period, flocculation characteristics may have differed during the two measurement periods, or the organic material could have influenced the acoustic signal differently than the optical signal. As noted earlier, flocculation would likely modify the optical and acoustic signals to different degrees, and could lead to the bifurcation evident in Figure 9. The floc size and fall speed data may shed some light on this hypothesis once available. 


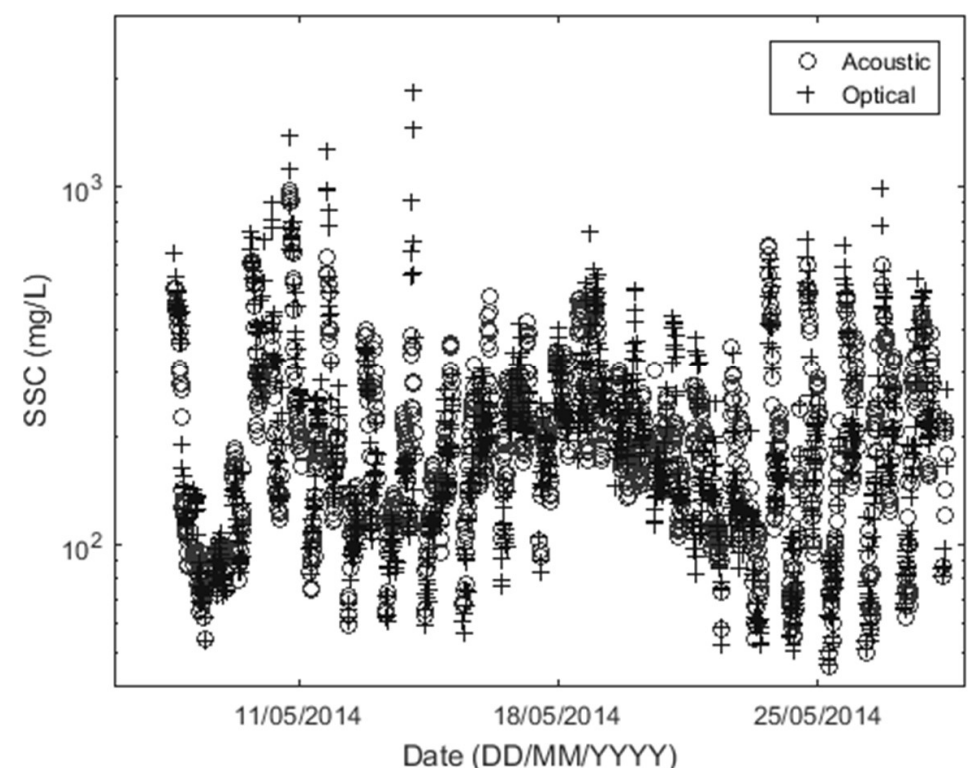

Figure 7. Time series of acoustically (red circles) and optically (blue crosses) estimated values of SSC for May 7 28 dataset.

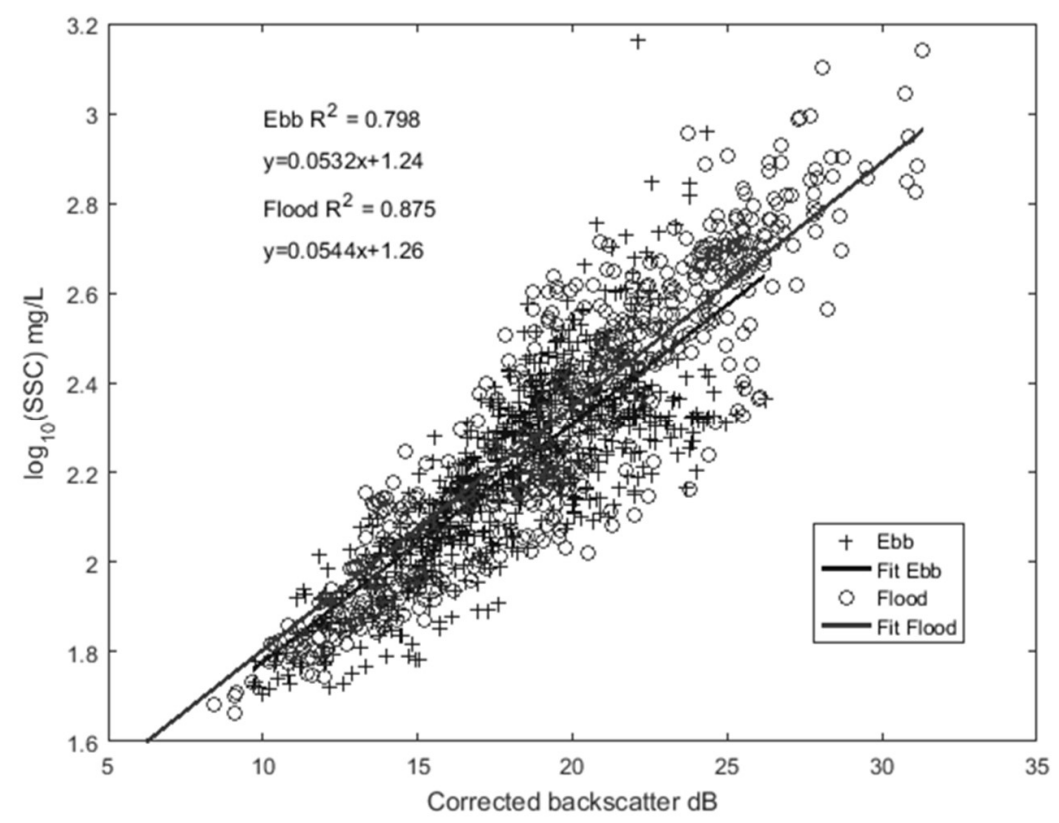

Figure 8. Optically derived SSC vs. relative backscatter, segregated by sign of flow, May 7-28. 


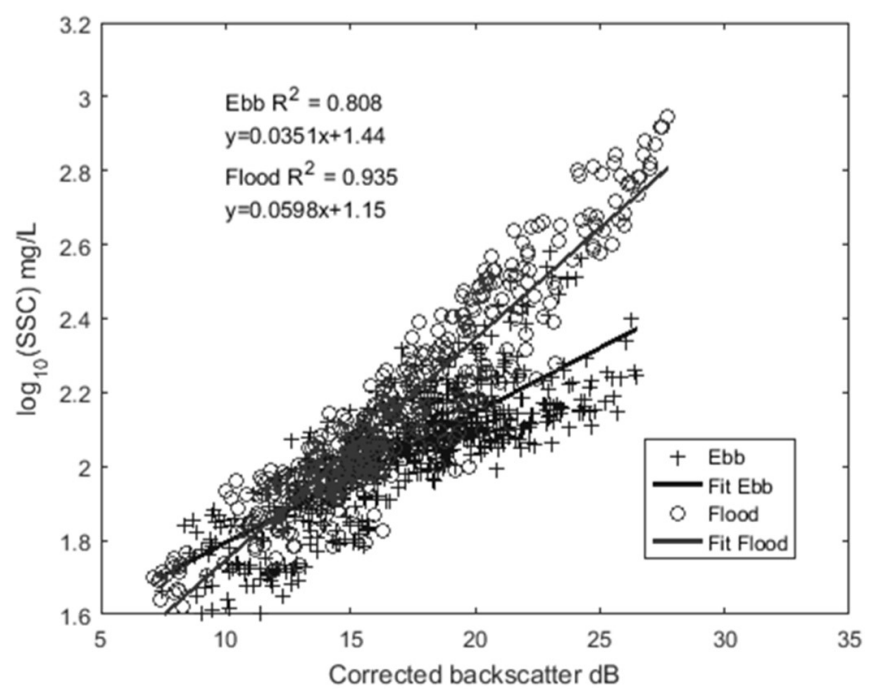

Figure 9. Optically derived SSC vs. relative backscatter, segregated by sign of flow, March 26-April 15.

\section{CONCLUSIONS}

Optical turbidity sensors have been used for many years as a proxy for suspended sediment concentrations. While not perfect, they work well if calibrated and maintained regularly, if properties of the suspended sediment are reasonably constant.

Acoustic methods, however, have received increased attention of late, primarily for two reasons: 1) they are much less susceptible to signal degradation due to fouling, and 2) using the same sensor for both velocity (very often desired for computing sediment flux or for other reasons) and SSC can reduce hardware costs and maintenance requirements. The US Geological Survey has recently released guidance on how to properly use acoustic sensors for estimation of SSC (Landers et al. 2016).

To investigate the suitability of the approach in an estuary environment, subject to regular inflows of salt water from an ocean boundary, periodic freshwater inflows, and wind forcing, a tripod was deployed on a mudflat in south San Francisco Bay. The tripod was deployed from March to May, 2014, logging optical turbidity, stage, water temperature, chlorophyll, and acoustic estimates of $3 \mathrm{D}$ velocity at a point, with corresponding backscatter and noise data. The optical turbidity data were converted to SSC using empirical relations derived for a nearby site. Relative acoustic backscatter was computed by subtracting reported noise from the measured backscatter, and then an empirical relationship established between the relative backscatter and the optically derived SSC values.

The degree of agreement between optically and acoustically estimated values of SSC varied, depending on the time period considered. Both methods were able to produce the same general trends in the time series, but the acoustic approach revealed differences between ebb and flood conditions that were not evident at all times, and were not evident in the optical estimates. It is hypothesized that flocculation is one reason for this and that the flocculation has different impacts on the acoustic and optical signals and also exhibits some time dependence at the site considered here. Previous work at the site did reveal that flocculation is significant on the tidal time scale and that floc sizes can vary by at least a factor of four. Additional work will be required to explain the differences that are evident in the dataset on a tidal time scale, with the significance of this tidal time scale difference following a seasonal time scale.

Any device used as a proxy for SSC is going to have some uncertainty and pros and cons. The acoustic approach has enough merit to warrant further investigation to improve predictions of SSC from backscatter throughout the year at sites subjected to tidal flow and fine sediments that periodically flocculate. It will be important to use acoustic frequencies that are a suitable match for the sediments of interest. Frequencies chosen to yield a suitable range for measurement of velocity (typically $\mathrm{O}(1 \mathrm{MHz})$ ) are often too low to be well suited for measurement of suspended sediment (where $\mathrm{O}(10 \mathrm{MHz}$ ) is better). Multiple acoustic devices, or one device capable of operating at multiple frequencies, might be a solution to this problem, and would still have significant advantages over the optical approach. 


\section{ACKNOWLEDGEMENTS}

This research was completed with support from the Scientific and Research Council of Turkey (TUBITAK)

\section{REFERENCES}

Alvarez, L. G., and S. E. Jones. 2002. Factors influencing suspended sediment flux in the upper Gulf of California. Coastal and Shelf Sci, 54:747-759.

Buchanan, P.A., and T.L. Morgan. 2012. Summary of suspended-sediment concentration data, San Francisco Bay, California, Water Year 2009: U.S. Geological Survey Data Series 744, 26 p.

Buchanan, P.A., and T.L. Morgan. 2014. Summary of suspended-sediment concentration data, San Francisco Bay, California, Water Year 2010: U.S. Geological Survey Data Series 808, 30 p., DOI: http://dx.doi.org/10.3133/ds808.

Conomos, T.J. 1963. Geologic aspects of the recent sediments of South San Francisco Bay, Master of Science Thesis, San Jose State College, San Jose, CA, USA, 118 pp.

Conomos, T.J., R.E. Smith, and J.W. Gartner. 1985. Environmental setting of San Francisco Bay. Hydrobiologia, 129, $1-12$.

Elci, Ş., R. Aydın, and P.A. Work. 2009. Estimation of suspended sediment concentration in rivers using acoustic methods. Environ Monit Assess, 159, 255-265.

Gartner, J.W. 2004. Estimating suspended solids concentrations from backscatter intensity measured by acoustic Doppler current profiler in San Francisco Bay, California. Mar Geol, 211(3), 169-187.

Hamilton, L.J., Z. Shi, and S.Y. Zhang. 1998. Acoustic backscatter measurements of estuarine suspended cohesive sediment concentration profiles. J Coastal Res, 14(4), 1213-1224.

Hay, A.E. 1991. Sound scattering from a particle-laden turbulent jet. J Acoust Soc Am, 90, 2055-2074.

Hay, A.E. and J. Sheng. 1992. Vertical profiles of suspended sand concentration and size from multifrequency acoustic backscatter. J Geophys Res, 97(C10), 15661-15677.

Hosseini, S.A., A. Shamsai, and B. Ataie-Astiani. 2005. Synchronous measurements of the velocity and concentration in low density turbidity currents using an acoustic Doppler velocimeter. Flow Meas Instrum, 17, 59-68.

Jaffe, B., A. Foxgrover, and D. Finlayson. 2011. Mudflat loss during South San Francisco Bay salt pond restoration: regional and global perspectives on initial post-restoration changes. South Bay Science Symposium, CA, USA.

Knebel, H.J., T.J. Conomos, and J.A. Commeau. 1977. Clay-mineral variability in the suspended sediments of the San Francisco Bay system, California. Journal of Sedimentary Petrology, 47,229236.

Landers, M.N., T.D. Straub, M.S. Wood, and M.M. Domanski. 2016, Sediment acoustic index method for computing continuous suspended-sediment concentrations: U.S. Geological Survey Techniques and Methods, book 3, chap. C5, 63 p., http://dx.doi.org/10.3133/tm3C5.

MacDonald, I.T., C.E. Vincent, P.D. Thorne, and P.D. Moate. 2013. Acoustic scattering from a suspension of flocculated sediments. J Geophys Res, Oceans, 118, 1-14.

Porterfield, G. 1980. Sediment transport of streams tributary to San Francisco, San Pablo, and Suisun Bays, California, 1909-1966. U.S. Geological Survey Water Resources Investigations 80-64.

Schulkin, M., and H.W. Marsh. 1962. Sound absorption in sea water. Journal of the Acoustical Society of America, 34(6), 864-865.

Shellenbarger, G.G., S.A. Wright, and D.H. Schoellhamer. 2013. A sediment budget for the southern reach in San Francisco Bay, CA: implications for habitat restoration. Mar Geo, 345:281-293.

SonTek. 1998. Doppler current meters: Using signal strength to monitor suspended sediment concentration. Technical Note, SonTek Inc., San Diego, CA, USA.

Thevenot, M.M., T.L. Prickett, and N.C. Kraus. 1992. Tylers Beach, Virginia, dredged material plume monitoring project, 27 September to 4 October 1991. Dredging Research Program Technical Report DRP-92-7, US Army Corps of Engineers, Washington, DC, 204 pp.

Thorne, P.D. and P.J. Hardcastle. 1997. Acoustic measurements of suspended sediments in turbulent currents and comparison with in-situ samples. J Acoust Soc Am, 101, 2603-2614.

Thorne, P.D., and D.M. Hanes. 2002. A review of acoustic measurement of small-scale sediment processes. Cont Shelf Res, 22(4), 603-632.

Urick, R.J. 1948. The absorption of sound in suspensions of irregular particles, J. Acoust. Soc. Am., 20(3), 283-289. 
Urick, R.J. 1975. Principles of Underwater Sound. McGraw-Hill Inc., New York, US.

Wright, S.A., and D.H. Schoellhamer. 2004. Trends in the sediment yield of the Sacramento River, California, 1957-2001. San Francisco Estuary and Watershed Science, 2. http://repositories. cdlib.org/jmie/sfews/vol2/iss2/art2.

Xavier, B.C, C.P. Ribeiro, L.G. Guimaraes,, M.G. Gallo, and A.G. Figueiredo, Jr. 2015. Estimation of suspended sediment concentration by acoustic calibration and scattering properties: an experimental and theoretical analysis. IEEE/OES Acoustics in Underwater Geosciences Symposium, Rio de Janeiro, Brasil, July 29-31. 